\title{
Propuesta de un modelo de creación de valor para medir la expansión y el crecimiento en la universidad pública
}

A value creation model proposal for measuring the expansion and growth in the public university

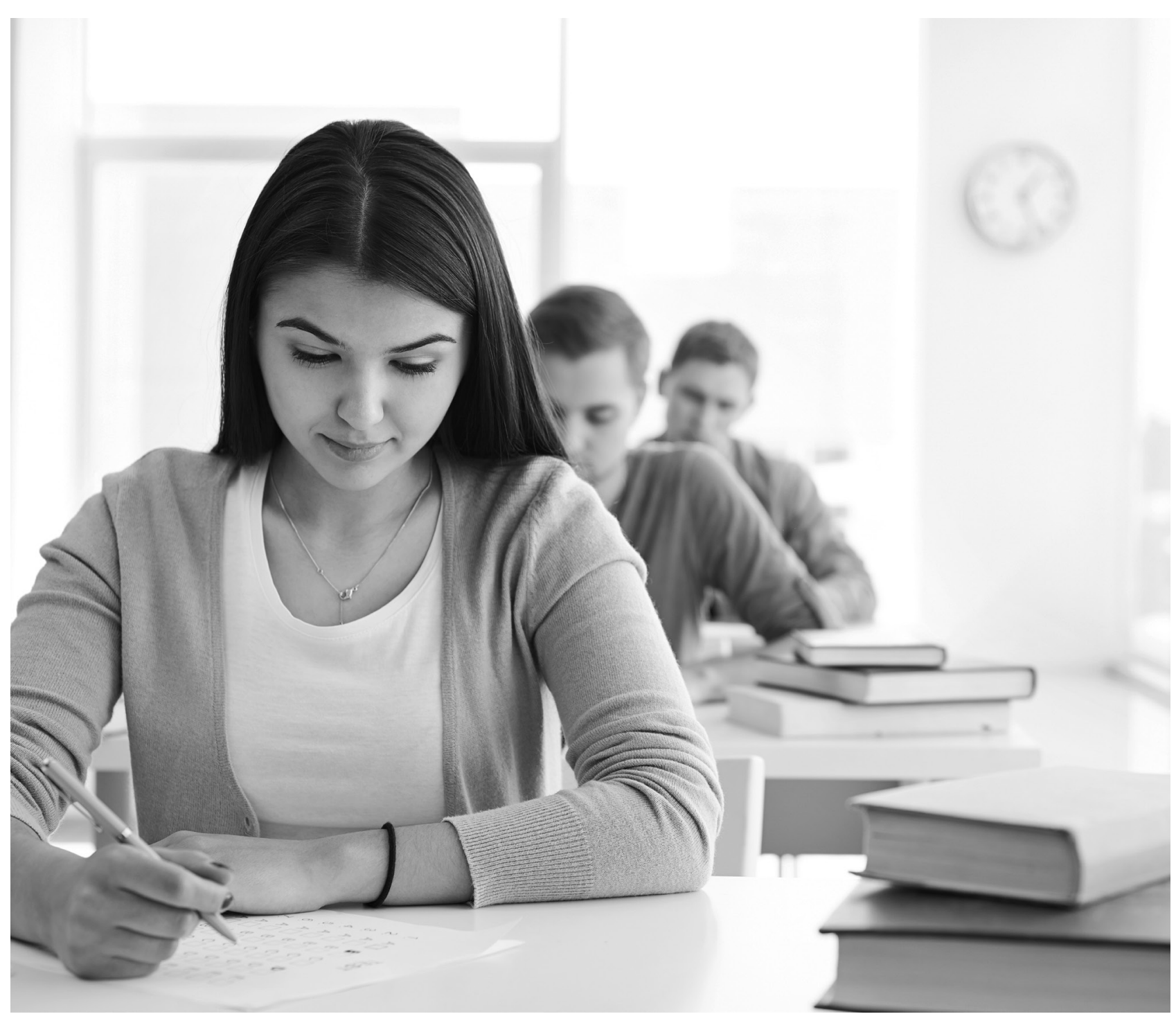




\title{
Propuesta de un modelo de creación de valor para medir la expansión y el crecimiento en la universidad pública ${ }^{1}$ A value creation model proposal for measuring the expansion and growth in the public university
}

\author{
Carlos Alberto Chica Salgado², Miryam del Pilar Soto Durán ${ }^{3}$
}

Artículo recibido en agosto 10 de 2017; artículo aceptado en septiembre 27 de 2018.

Este artículo puede compartirse bajo la Licencia Creative Commons Atribución-NoComercial-Compartirlgual 4.0 Internacional

y se referencia usando el siguiente formato: Chica, C. A. \& Soto, M. P. (2019). Propuesta de un modelo de creación de valor

para medir la expansión y el crecimiento en la universidad pública. I+D Revista de Investigaciones, 14 (2), 17-32.

DOI: https://doi.org/10.33304/revinv.v14n2-2019002

\section{Resumen}

El objetivo de este artículo es presentar la propuesta de un modelo de creación de valor en la universidad pública, a través del resultado del acercamiento a la revisión teórica de la gestión de inductores de valor y la palanca de crecimiento. Esto se sustenta en una adecuada planeación financiera, así como en un eficiente control de la gestión financiera que utilice los inductores de valor y que permita la eficacia y eficiencia en el proceso de la educación superior pública. Para tal fin, fue necesario indagar las fuentes de recursos propios y describir la evolución del presupuesto de ingresos y gastos; de igual forma, analizar la liquidez y el capital de trabajo, con relación al manejo de los ingresos con recursos propios, para luego comparar el comportamiento de la productividad de los activos fijos sobre la liquidez y el capital de trabajo orientados hacia la creación de valor en la universidad pública.

Palabras clave: Creación de valor, inductores de valor, palanca de crecimiento, rentabilidad.

\begin{abstract}
The aim of this article is to share the proposal of a model of value creation for the public university, through the outcome of an approximation to the theoretical review of the value inductors management and the level of growth. This is based on an adequate financial planning, as well as on an efficient control of financial management, which uses value drivers and allows efficiency and effectiveness in the process of public higher education. For this purpose, it was necessary to investigate the sources of their own resources; to describe the evolution of the budget of income and expenses; to analyze the liquidity and working capital, in relation to the management of income with their own resources, in order to compare the behavior of the productivity of fixed assets over liquidity and working capital,

1. Artículo teórico, cuyo tipo de enfoque se enmarca en el ámbito cuantitativo, resultado del acercamiento a la revisión teórica de los inductores de valor y la palanca de crecimiento. Perteneciente al área de ciencias socioeconómicas, subárea finanzas.

2. Administrador de Empresas, Universidad Nacional de Colombia. Magíster en Administración, Universidad Nacional de Colombia. Docente asociado e investigador júnior del grupo Gestión del Desarrollo Agrario (Gestiagro). Politécnico Colombiano Jaime Isaza Cadavid, de la ciudad de Medellín (Colombia). Dirección: calle 48 n. ${ }^{\circ}$ 7-151, PBX: 3197900, ext. 426. ORCID ID: https://orcid.org/0000-0002-5971-7706. Correo electrónico institucional: casalgado@elpoli.edu.co.

3. Contadora pública, Universidad Francisco de Paula Santander. Magíster en Gerencia de Empresas, mención finanzas, Universidad Nacional Experimental del Táchira. Docente y coinvestigadora de la línea gestión financiera agropecuaria, del grupo Gefinagro. Politécnico Colombiano Jaime Isaza Cadavid, de la ciudad de Medellín (Colombia). Dirección: calle 48 n. 7-151, PBX: 3197900. ORCID ID: https://orcid.org/0000-0002-47292835. Correo electrónico institucional: miryam.soto@uniminuto.edu.co.
\end{abstract}


oriented towards the creation of value in the public university.

Keywords: Creation of value, inductors of value, lever of growth, profitability.

\section{Introducción}

En la actualidad, la gestión en las universidades públicas requiere un cambio de mentalidad en sus niveles directivos, sobre todo en lo que se refiere al ámbito de la creación de valor, para que sean instituciones innovadoras y competitivas en la oferta académica que hacen a un público objetivo. Por esto, la gestión orientada hacia la excelencia en el manejo de los recursos debe ir a la par con los procesos de expansión y crecimiento.

La universidad pública tiene como propósito misional lograr una educación de calidad, a través de la docencia, la extensión yla proyección social e investigación, queforman parte integral de la misión educativa de las instituciones de educación superior (Paz-Marcano, Sánchez-González \& Sánchez-Valbuena, 2018). Para cumplir con su objetivo, necesita recursos materiales, financieros y humanos, para su proceso de expansión y crecimiento, de acuerdo con su plan institucional de desarrollo.

En el nuevo entorno, la competitividad de las universidades públicas se ve comprometida por dos aspectos interrelacionados entre sí. El primero, un uso intensivo y racional de las tecnologías de información (TI) que cree valor para la institución y apoyo directo. El segundo, el conocimiento como recurso fundamental de las organizaciones (Pérez González, 2005; Simanca, Porras, Garrido \& Hernández, 2017). Los dos aspectos se desprenden del ámbito de la teoría de la gerencia basada en el valor (GBV).

\section{Contexto de la creación de valor en una institución educativa universitaria}

La creación de valor en las instituciones de educación superior está dada por la capacidad que tienen los proyectos adelantados por estas organizaciones de producir beneficios a un mayor sector de la población. Estos beneficios multiplican los recursos invertidos para dar solución a las necesidades sociales de alto impacto (Porter \& Kramer, 2006).

La creación de valor como criterio para la toma de decisiones en la universidad pública está presente en el área de la planificación financiera de las nuevas inversiones. Se plantea que los resultados de la empresa deben evaluarse de acuerdo con su contribución a la creación o destrucción de valor de la inversión de recursos realizada por los propietarios como una conveniente filosofía de la gestión empresarial (Vera Colina, 2006).

Las instituciones universitarias actúan según políticas y principios de una planeación universitaria, como el instrumento fundamental para el cambio y el desarrollo institucional, bajo los siguientes compromisos:

1. Evaluar de forma permanente la gestión de los órganos administrativos y académicos.

2. Establecer las estrategias sobre la base de una adecuada planeación en el mediano plazo.

3. Elevar los niveles de eficiencia en el uso de los recursos (Didriksson, 2005).

Por tanto, la planificación financiera en las instituciones universitarias públicas, así como su funcionamiento como factor clave en la creación de valor-además de la financiación y los costos asociados para poder realizar sus actividades- requieren recursos financieros para desarrollar sus funciones misionales actuales o para ampliarlas. A su vez, requieren nuevos proyectos que impliquen inversión y les permita obtener recursos económicos, ya sean propios o ajenos (Rodríguez Martín, 2004).

Dentro de las prioridades de la administración en una institución de educación superior, y siguiendo los lineamientos de una sana administración financiera, puede inferirse que hay destrucción de valor, por la omisión de una adecuada planificación financiera. La institución está inmersa en los lineamientos del ámbito de la gestión financiera, que comprende la generación de ingresos, la eficiencia en el uso de los recursos y la reducción de costos (García Serna, 2009).

Las instituciones universitarias, en un contexto general y en el ámbito global de su administración, podrían generar destrucción de valor cuando carecen de políticas en la toma de decisiones alusivas a los planes de expansión sustentados en las inversiones en activos fijos que permitan obtener su rentabilidad y riesgo. La ausencia de planes concebidos para los procesos de expansión trae como consecuencia problemas de iliquidez, lo que afecta directamente la administración del capital de trabajo.

Cuanto mayor sea la cantidad de activos circulantes existentes en una institución universitaria, más alta es la probabilidad de que algunos de ellos puedan convertirse en efectivo para pagar una deuda vencida. 
Esta situación permitiría un manejo financiero para el pago de los compromisos institucionales asumidos por las universidades (Gitman \& Zutter, 2012).

\section{La creación de valor como reto de la administración en la universidad pública colombiana}

En el contexto actual, las instituciones universitarias tienen el reto de enfocarse hacia la generación de valor. Para ello, deben basarse en el cumplimiento de un objetivo financiero que conduzca a la maximización del beneficio de la sociedad, en especial para la universidad como institución pública. El valor agregado de la institución debe reflejarse en el resultado de sus indicadores financieros y en el manejo eficiente de los recursos públicos. Esto impactará de forma positiva tanto en su público interno como externo.

La gerencia basada en el valor (GBV) involucra a la planeación estratégica o a la dirección, con el propósito de que la institución obtenga los resultados financieros esperados. Para que la gerencia del valor sea exitosa, se requiere que su filosofía sea integrada en la manera en que se toman las decisiones en la institución universitaria (Rincón de Parra, 2005).

El objetivo de un proceso de medición de creación de valor económico en una institución universitaria debe comprender los siguientes aspectos (Calva Mercado, 2001):

- Asegurar que los beneficios generados por la institución son lo suficientemente considerables como para cubrir el costo de las fuentes de financiamiento y de los recursos invertidos en las dinámicas de operación de sus procesos misionales.

- Dotar de un medidor a los consejos directivos, a la administración y a todos los niveles de la institución, para asegurar que todas las áreas y unidades ayuden a la creación de valor.

- Apoyar el desarrollo de esquemas de compensación, a través de estímulos con los que se busque relacionar el desempeño con los logros alcanzados por la institución.

Estos aspectos tienden en su integralidad a lograr un cambio en la estructura de financiamiento de la institución. Al hacer la asignación de recursos, la institución deberá tener asociados unos indicadores de desempeño que le permitan medir los resultados obtenidos, según la distribución hecha.

La valoración desde la orientación de la creación del valor se refiere a la rentabilidad del activo con respecto a la inversión inicial, lo que implica la generación futura de flujos de caja para garantizar la permanencia, la sostenibilidad y el crecimiento de la institución universitaria. Esto es, un crecimiento que le permita la inversión de capital a futuro (Garcia, 2009). De esta forma, la creación de valor se realiza mediante inversiones de capital (Van Horne \& Wachowicz, 2010).

\section{Inductores de valor, palanca de crecimiento y otros criterios de la creación de valor}

La institución de educación superior debe determinar cuál o cuáles son las variables asociadas con su actividad económica. Esto es, cuáles son las variables que más inciden o afectan su valor, con el fin de promover en todos los niveles de la estructura organizacional el alineamiento de las decisiones hacia la mejora permanente de esas variables. A estos aspectos se les ha denominado inductores de valor.

La palanca de crecimiento es un indicador que le permite a la universidad analizar el momento real y la optimización del crecimiento en cada periodo. Hace referencia al equilibrio entre el EBITDA y la productividad del capital de trabajo neto operativo. Como indicador, permite medir el crecimiento y la creación de valor en la institución universitaria.

Este trabajo orientado para las instituciones de educación superior propone un modelo de creación de valor que permita analizar de manera más adecuada el desarrollo de la institución, a través de los inductores de valor. Entre estos, se destacan el EBITDA, el margen EBITDA, la productividad de capital de trabajo y la palanca de crecimiento. Este último indicador refleja qué tan atractivo es para la institución universitaria crecer, desde el punto de vista de la generación de valor. Lo ideal es que el PDC sea mayor a uno, para que el crecimiento libere caja. Por el contrario, si es menor a uno, al momento de crecer deja de ser rentable.

Los recursos invertidos en activos fijos deben ser productivos para que se conviertan en un inductor que cree valor. A su vez, las inversiones hechas por las organizaciones están conformadas por los siguientes inductores de valor. Estos conforman parte de la planeación financiera dirigida hacia la creación de valor, a través de la rentabilidad (Soto Durán, 2010):
- Productividad del activo fijo
- Productividad del capital de trabajo
- Margen EBITDA
- Palanca de crecimiento

\section{Productividad del activo fijo (PAF)}

La inversión en activos fijos destinados a los planes de 
expansión de la universidad pública tiene como finalidad la adquisición de bienes tangibles y duraderos. Se trata de bienes de equipo o instrumentos para el servicio educativo que la institución universitaria utilizará durante varios años, a fin de cumplir con su objetivo misional. La propiedad de planta y equipo la constituyen los bienes tangibles adquiridos por la institución, con el objeto de desarrollar su función. Estos contribuyen a la generación de ingresos que se representan en el tiempo en que se desarrollan las actividades de docencia, extensión o proyección social e investigación (Soto Durán, 2010).

Los activos fijos se caracterizan por ser de larga vida. Se adquieren con la finalidad de utilizarlos en las operaciones y la actividad del objeto social de la universidad. Normalmente proporcionan a la institución de educación superior muchos años de servicio productivo, dado que representan una inversión significativa de sus recursos financieros. Se consideran estos activos como una corriente de servicios futuros, por lo que estas inversiones deben comprender un destino en la creación de valor (Meigs et al., 2001).

La importancia del inductor operativo denominado productividad del activo fijo refleja la eficiencia en el aprovechamiento de la capacidad instalada de la institución. Se expresa como la capacidad de generar ingresos, dada una determinada inversión en dichos activos. Su valor se calcula a través de la siguiente formulación (García Serna, 2009):

$$
P A F=\frac{\text { Ingresos }}{\text { Activos fijos }}
$$

Los criterios que prescriben las NIIF para la incorporación de activos fijos al patrimonio abordan las consecuencias de la elección del criterio valorativo, así como el tratamiento previsto ante el eventual cambio de uso que pueden experimentar a lo largo de su vida útil. De ahí la importancia del criterio valorativo y de reconocimiento aplicado en las normas internacionales para la medición de los activos fijos (Otal Franco \& Serrano García, 2006).

\section{Productividad del capital de trabajo (PKT)}

La productividad del capital de trabajo como inductor operativo radica en que este refleja lo que la universidad debe mantener invertido en capital de trabajo por cada peso de los ingresos obtenidos (García Serna, 2009). En este sentido, el capital de trabajo es fundamental, porque determina el nivel de productividad y de continuidad de la institución de educación superior. Además, debe ser un inductor que cree valor.
La productividad del capital de trabajo se define como la eficiencia con la que se aprovechan los recursos corrientes de la universidad. Se calcula dividiendo el capital de trabajo neto operativo (KTNO) entre sus ingresos. Se interpreta como los centavos que deben mantenerse en capital de trabajo por cada unidad monetaria percibida como ingreso (García Serna, 2009).

\section{Margen EBITDA}

El margen EBITDA se concibe como la utilidad operativa obtenida antes de descontar las depreciaciones, amortizaciones de gastos y gastos pagados por anticipado (García, 2009). Se obtiene dividiendo esta utilidad operativa entre los ingresos. Muestra lo que de cada unidad monetaria de ingresos se convierte en caja bruta, para posteriormente destinarse al cubrimiento de los ingresos, atender el servicio a la deuda y apoyar las inversiones para la reposición de activos y el crecimiento de la institución de educación superior.

Es necesario resaltar que cuanto mayor sea este margen, mayores serán las posibilidades de generación de valor.

\section{Palanca de crecimiento (PDC)}

La palanca de crecimiento (PDC) corresponde a la relación entre el margen EBITDA y la productividad del capital de trabajo. De igual forma, la relación que se da entre los dos elementos mencionados es la siguiente:

- a) Si el resultado obtenido es mayor que uno, la PDC es favorable para la universidad, y el crecimiento genera valor. Implica que en la medida en que la institución de educación superior crece, libera más efectivo, lo que mejora la liquidez y la posibilidad de cumplir con sus compromisos.

- b) Si el resultado obtenido es menor que uno, la PDC es desfavorable para la institución de educación superior, y el crecimiento no genera valor. Implica que en la medida en que la universidad crece, en lugar de liberar efectivo, se consume el de periodos anteriores. Se configura así un desbalance en el flujo de caja, lo que impide que se cumpla adecuadamente con los compromisos de pago de los impuestos, la carga financiera y la reposición de activos fijos, entre otras obligaciones.

\section{La planificación presupuestaria en la universidad pública}

El presupuesto es una herramienta financiera que determina el control de los recursos propios en una 
institución de educación superior. Esta herramienta de índole financiera permite a las vicerrectorías administrativas planear las operaciones para el cumplimiento de las funciones misionales, con lo que garantizan el crecimiento y rentabilidad. El presupuesto público es la garantía del cumplimiento de los planes y programas de desarrollo y de inversión que realiza la universidad pública (Soto Durán, 2010).

En el estatuto de presupuesto de la universidad pública están contenidas las normas que regulan la programación, aprobación, modificación y ejecución del presupuesto de la universidad. De la misma manera, en el estatuto se consignan las normas referidas a la coordinación, con el plan de desarrollo institucional, la definición del gasto social y la capacidad de la entidad para contratar (Ministerio de Educación Nacional, Ley 30 de 1992).

En la universidad pública, existen algunas clasificaciones presupuestarias o tipos de presupuestos. Algunas de estas son:

Presupuesto de ingresos: Comprende toda transacción que implica la generación de un medio de financiamiento o fuente de fondos que le garanticen ingresos a la institución de educación superior. El presupuesto de ingresos se revelará atendiendo las diferentes etapas y conceptos. Estos se clasifican en aprobado, por ejecutar, ejecutado y recaudos en efectivo -ejecución en papeles y otros, y reconocimientos-. De la misma manera, se identifican, entre otros, las diferentes clases de impuestos, los ingresos no tributarios, la venta de bienes y servicios, las transferencias y los recursos del crédito (Romero, 2003).

Presupuesto de caja: Se define como el cálculo de todos los ingresos y egresos en efectivo que produce la institución. De sus resultados depende el desarrollo normal de las actividades necesarias para su funcionamiento. La evaluación de las entradas y salidas de efectivo hace posible el análisis de dos situaciones. La primera, la planificación de efectivo sobrante para obtener rentabilidad. La segunda, la necesidad de financiación para cubrir el déficit de efectivo (Burbano Ruíz, 2010).

Presupuesto de gastos: Corresponde a toda transacción que implica su aplicación financiera o uso de fondos. Las cuentas del presupuesto de gastos se revelarán en función de los criterios de la vigencia fiscal a la que se relaciona la apropiación. Se definen como actual, anterior y futura. Allí se identifican los diferentes conceptos de gastos de funcionamiento, servicio a la deuda e inversión (Burbano Ruíz, 2010).

Presupuesto de capital o de inversión: Es aquel destinado a hacer una inversión de capital. Con él se incurre en una salida de efectivo anual, y se espera, a cambio, beneficios futuros (Van Horne \& Wachowicz, 2010). Los gastos de inversión son ejecutados por el Gobierno nacional, departamental, distrital o municipal. Esto para el cumplimiento de los respectivos planes y programas de desarrollo económico y social de la sociedad tendientes a elevar la calidad de vida.

\section{La liquidez, administración del capital de trabajo y rentabilidad}

El concepto de 'liquidez' hace alusión a las veces en que el activo corriente cubre el pasivo corriente. A través de este indicador, se mide el flujo de efectivo constante que permite cancelar las obligaciones a corto y largo plazo. Con ello se logra una financiación adecuada para el desarrollo de los objetivos misionales que le garantizan la estabilidad financiera. La liquidez representa la cualidad de los activos para ser convertidos en efectivo de forma inmediata y sin pérdida significativa de su valor; es decir, la liquidez es la capacidad de la institución para satisfacer obligaciones a corto plazo, conforme vayan ocurriendo los vencimientos (Gitman \& Zutter, 2012).

En la liquidez como aspecto de la creación de valor existe el macro inductor flujo de caja libre. Este se ha convertido hoy en día en un indicador de medida financiera. Se refiere a que, a perpetuidad, el valor de la institución de educación superior es igual al valor presente de los futuros flujos de caja (García Serna, 2009).

La administración del capital de trabajo se fundamenta en el mantenimiento del suficiente efectivo que responda a las necesidades financieras, representado en los activos circulantes. Uno de sus propósitos es cubrir los requerimientos en el caso de las universidades públicas para el cumplimiento de sus procesos misionales.

\section{Metodología para la propuesta de construcción de un modelo de creación de valor}

El marco metodológico para definir la propuesta del modelo de creación de valor comprendió los siguientes aspectos (Soto Durán, 2010).

Diseño de la investigación. Este trabajo de investigación se fundamentó en el diseño documental, basado en la búsqueda, recuperación, análisis, critica e interpretación de los datos secundarios -presupuestos, estados financieros auditados, recaudos-, que se consideraron útiles para los diferentes componentes y otros documentos emitidos por la Universidad de Pamplona, institución de educación superior de carácter público de 
orden departamental. Fue también una investigación de carácter no experimental, debido a que las variables no fueron manipuladas.

Los datos de la información fueron analizados mediante la utilización de la estadística descriptiva, para medir y describir los comportamientos entre las variables fuentes de recursos propios, presupuestos de ingresos y gastos, liquidez, capital de trabajo y activos fijos, durante un periodo de tiempo $(\mathrm{t})$ correspondiente a cinco años. Esto es, desde el año base $\mathrm{i}=1$ hasta $\mathrm{t}=5,\left(t_{i=1}^{5}\right)$, en donde el análisis documental estuvo presente durante todo el proceso.

Población y muestra. La población la constituyó la información de tipo económico-financiera de la institución de educación superior vinculada a las variables del estudio. La muestra estuvo representada por los estados financieros y los presupuestos correspondientes al periodo de tiempo (t) de cinco años.

De este conjunto de datos se tomó una parte representativa, de acuerdo con los criterios específicos para el correspondiente análisis de las variables. Esto a través de la indagación exhaustiva, sistemática y rigurosa a la que fueron sometidos los documentos.

Técnicas e instrumentos para la recolección de los datos. La técnica utilizada fue el análisis de los estados financieros y presupuestos correspondientes. Se requirió entonces la observación no estructurada y el análisis de los contenidos. Las fuentes secundarias las constituyeron los documentos soporte de los estados financieros de la institución de educación superior.

Validez y confiabilidad. Para determinar la validez, se aplicó la técnica de juicio de expertos. Esto implicó solicitar la cooperación de profesionales versados en el área financiera, con el propósito de que coadyuvaran en las lecturas de los materiales producidos.

La confiabilidad estuvo relacionada con la mayor certeza con que se pudo verificar la existencia del fenómeno estadísticamente medible.

Procesamiento y análisis de datos. Los datos de la información financiera se analizaron mediante el software IBM SPSS Statistics para Windows SPSS18. Con el programa, se hizo uso de la estadística descriptiva para cada una de las variables. Con la información se elaboraron distribuciones de frecuencias, tanto relativas como acumuladas, histogramas y gráficas de tipo descriptivo.
En la Tabla 1 se presenta la operacionalización de las variables, según los respectivos componentes, con el propósito de poder determinar bajo la metodología propuesta un modelo para la creación de valor en una universidad pública.

\section{Análisis e interpretación de resultados}

A continuación, se presentan los resultados del análisis de la información, mediante la utilización de la estadística descriptiva. Esto se hace para medir y describir los comportamientos en el contexto de los respectivos subindicadores e indicadores asociados a las variables, fuentes de recursos propios, presupuestos de ingresos y gastos, liquidez, capital de trabajo y activos fijos, que permiten proponer un modelo de creación de valor para la universidad pública.

\section{Fuentes de recursos propios}

Encontramos, resultado de la recolección de la información, que se reconocen tres (3) grandes fuentes de financiación de los recursos propios para la Universidad de Pamplona:

1. Venta de los servicios educativos contentivos de matrículas. Las matrículas tienen la modalidad presencial, semipresencial, a distancia, posgrados, educación continua, diplomados, congresos, inscripciones, habilitaciones, certificaciones y programas especiales.

2. Otros servicios educativos. Estos se representan por los convenios que se han celebrado con entidades y universidades, que tienen una destinación específica del 90 $\%$. En esta operación se generan como ingresos o ganancias un intervalo entre el $5 \%$ y $10 \%$, por administración de los convenios.

3. Las transferencias. Estas correspondena las trasferencias del Gobierno nacional y las recibidas del departamento y de otras entidades, con libre destinación, para gastos de funcionamiento e inversión.

Las ejecuciones presupuestales activas están enmarcadas en los componentes del presupuesto que comprenden el presupuesto definitivo de ingresos, los reconocimientos y los recaudos de la universidad.

\section{Tendencia (crecimiento)}

En el Gráfico 1 se presenta la ejecución presupuestal activa en el rubro de ingresos. Allí se analiza un hallazgo significativo de crecimiento, y se destacan los periodos cuatro y cinco, por su incremento en el porcentaje anual del $26,71 \%$ y $37,71 \%$, respectivamente. Esto es, un total de $\$ 511,8$. 
El promedio anual del presupuesto definitivo ascendió a la suma de $\$ 102,36$, con una desviación de $+/-\$ 61,08$.
Esto permite estimar un intervalo de confianza del $95 \%$ para este subindicador $[\$ 26,52 ; \$ 178,2]$.

\section{Tabla 1}

Operacionalización de variables para el modelo propuesto de creación de valor

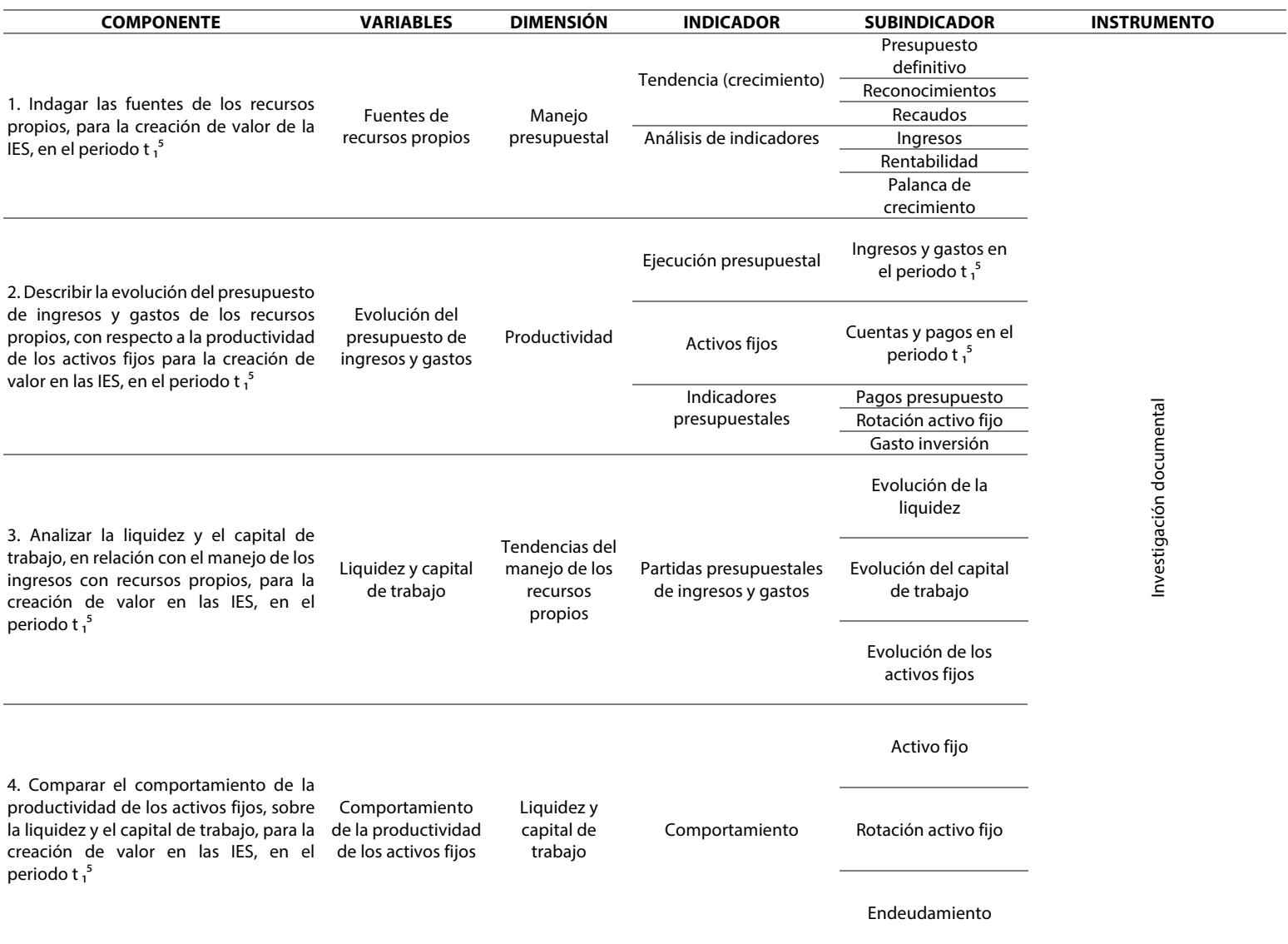

5. Proponer lineamientos

administrativos, para la creación de

valor en las IES, en el periodo $t_{1}{ }^{5}$
PROPUESTA

Fuente: Autores.

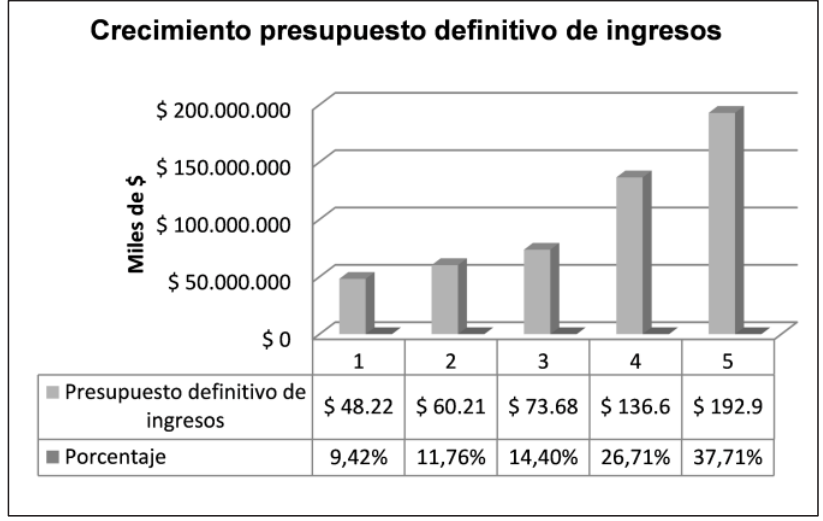

Gráfico 1.Crecimiento presupuesto definitivo de ingresos. Fuente: Universidad de Pamplona.

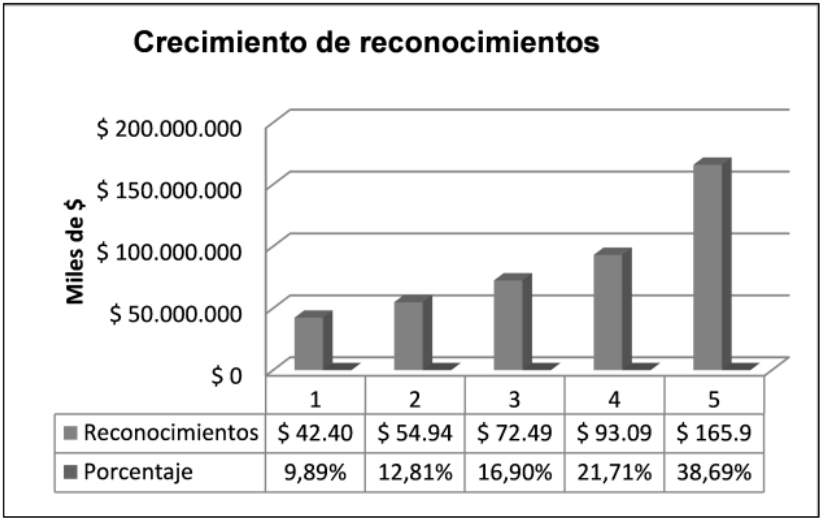

Gráfico 2. Crecimiento de los reconocimientos. Fuente: Universidad de Pamplona. 
En cuanto a los reconocimientos (ver Gráfico 2), se presenta un hallazgo significativo de crecimiento. Este corresponde a los periodos cuatro y cinco, por su incremento en el porcentaje anual, del 21,71 \% y 38,69 $\%$, de un valor total de $\$ 428,86$.

Los reconocimientos registraron un promedio anual de $\$ 85,77$, con una desviación de $+/-\$ 48,7$. Esto permite estimar un intervalo de confianza del $95 \%$ para este subindicador $[\$ 25,31 ; \$ 146,24]$.

El rubro de recaudos observado en el Gráfico 3 presenta un hallazgo significativo de crecimiento. Allí se destacan los periodos cuatro y cinco, por su incremento en el porcentaje anual, del $20,34 \%$ y $40,06 \%$, respectivamente, de un total de $\$ 393,58$.

El promedio anual de los recaudos definitivo ascendió a la suma de $\$ 78,72$, con una desviación de $+/-\$ 46,16$. Esto permite estimar un intervalo de confianza del $95 \%$ para este subindicador $[\$ 21,4 ; \$ 136,03]$.

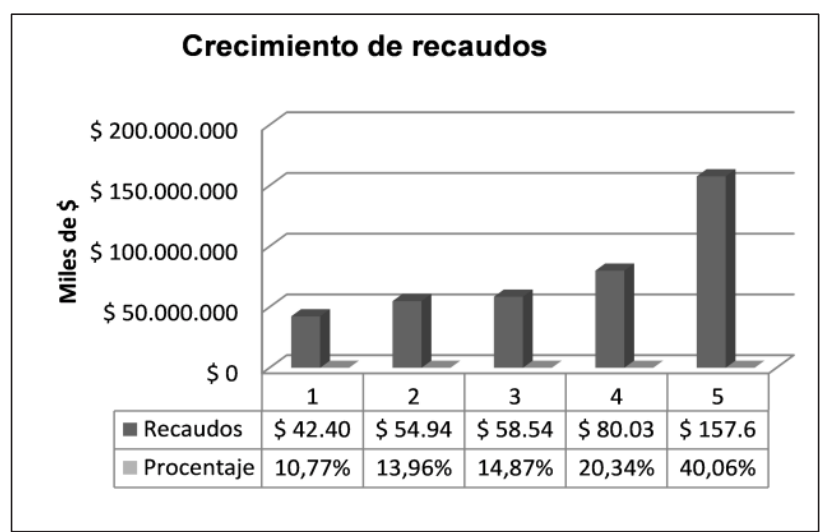

Gráfico 3. Crecimiento de los recaudos. Fuente:Universidad de Pamplona.

\section{Análisis de indicadores}

El indicador presupuestal se calculó según las siguientes formulaciones (ver 1 y 2), en relación con los ingresos o recaudos totales obtenidos por la universidad. Esto, respecto al presupuesto y los reconocimientos totales:

Indicador presupuestal $1(t)=\left(\frac{\text { Recaudos totales }}{\text { Presupuesto total }}\right)$

Indicador presupuestal $1(t)=\left(\frac{\text { Recaudos totales }}{\text { Presupuesto total }}\right)$

El indicador presupuestal 1, presentado en el Gráfico 4, indica que en el periodo dos se encuentra el mayor valor de los ingresos recaudados reales sobre los ingresos presupuestados. Esto es, equivalente al 91,25 \%; y en el periodo cuatro, se registra el menor valor del indicador, correspondiente al 58,55\%.

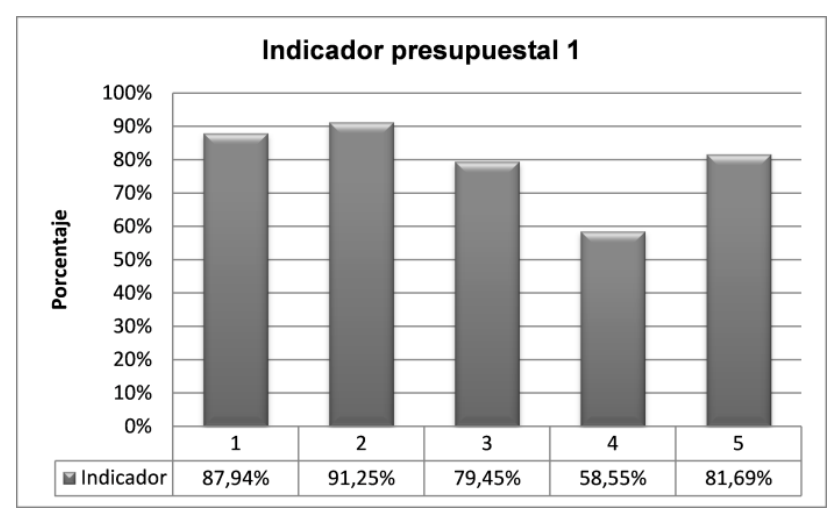

Gráfico 4. Indicador presupuestal 1. Fuente: Universidad de Pamplona.

En el Gráfico 5, el indicador presupuestal 2 explica que en los dos primeros periodos se encuentra el mayor valor de los ingresos recaudados reales. Esto frente al reconocimiento de una cuantía más alta que debe cobrarse de conformidad con los ingresos presupuestados y admitidos como ciertos, equivalente al $100 \%$. En el periodo tres se registra el menor valor del indicador correspondiente al 80,76\%.

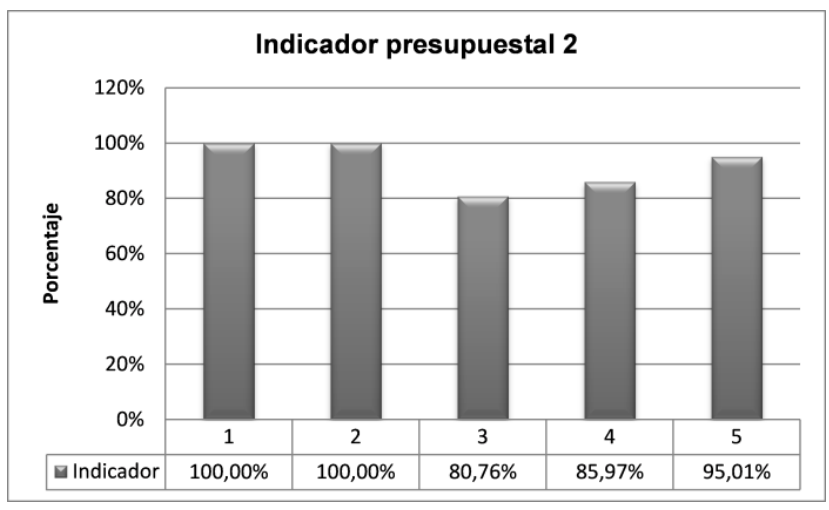

Gráfico 5. Indicador presupuestal 2. Fuente: Universidad de Pamplona.

En cuanto se refiere al subindicador de rentabilidad, se analizaron los comportamientos del rendimiento del activo total, del patrimonio, el porcentaje del margen de utilidad, los costos en relación con los ingresos y el rendimiento de los ingresos operacionales.

El rendimiento del activo total presentado en el Gráfico 6 midió la generación de utilidades de los activos totales de los que dispone la universidad, valorando la 
eficiencia de la gestión administrativa. Se observa un decrecimiento en el indicador hasta el cuarto periodo, lo que generó una disminución en la creación de valor.

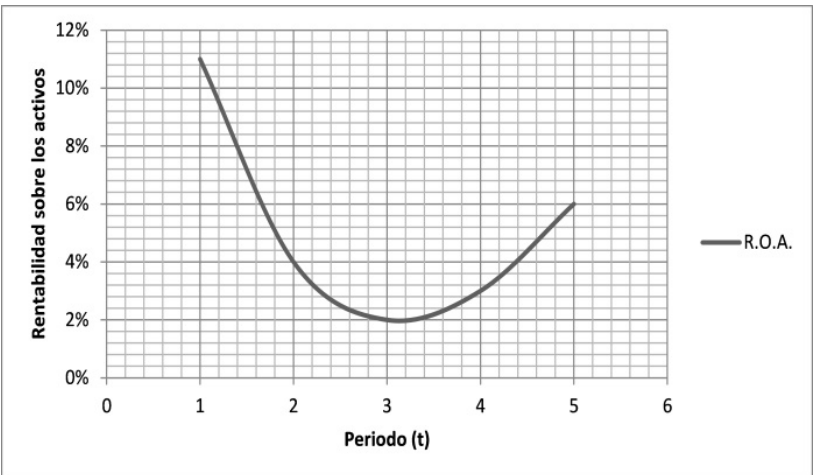

Gráfico 6. Rentabilidad sobre los activos. Fuente:Universidad de Pamplona.

El rendimiento del patrimonio que se presenta en el Gráfico 7 es otro indicador que determina la eficiencia de la gestión de la administración para la generación de utilidades en la institución de educación superior. Su comportamiento determinó igualmente una disminución hasta el periodo cuarto, lo que generó un decrecimiento en la creación de valor.

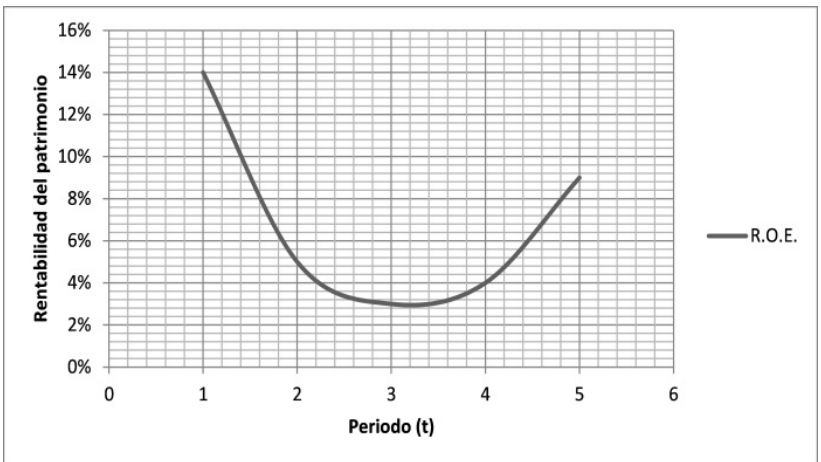

Gráfico 7. Rentabilidad del patrimonio. Fuente: Universidad de Pamplona.

El porcentaje del margen de utilidad significa el porcentaje de ganancia generado por las actividades de prestación del servicio asociadas a los ejes misionales de la universidad. En el Gráfico 8 se observa un decrecimiento en el indicador hasta el cuarto periodo. Este equivale a una disminución del valor en los rendimientos operacionales de utilidad neta de la institución de educación superior.

En cuanto a los costos en relación con los ingresos, como

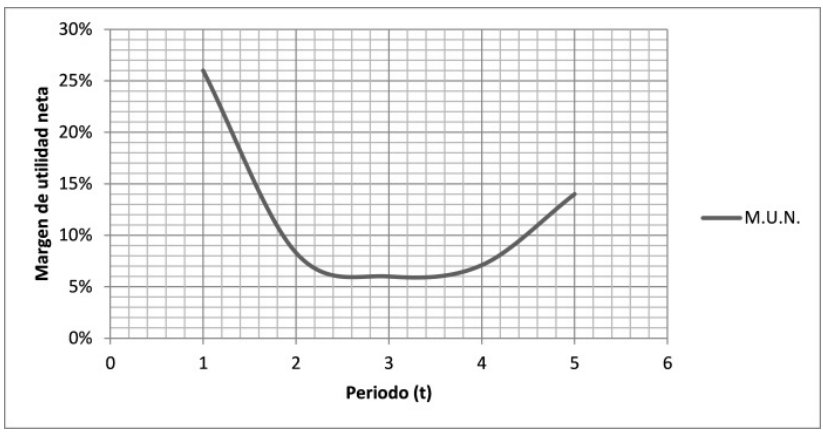

Gráfico 8. Margen de utilidad. Fuente: Universidad de Pamplona.

se observa en el Gráfico 9, a medida que se aumentaron los ingresos, en igual comportamiento lo hicieron los costos operativos asociados a las funciones misionales de la universidad, sin una medida de control efectiva en el manejo financiero.

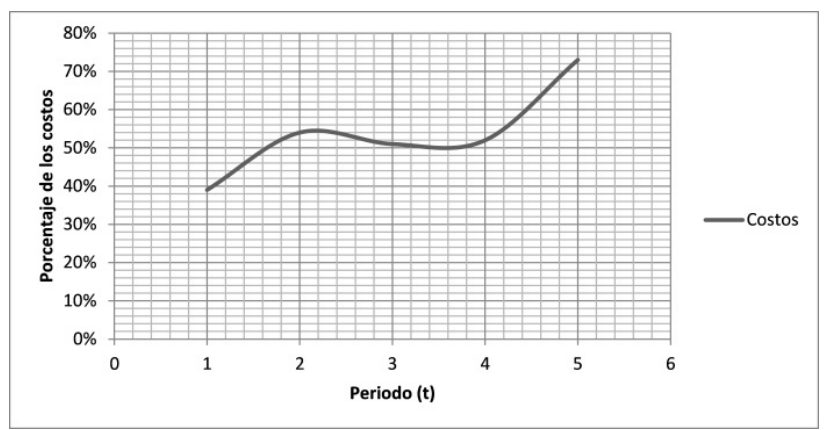

Gráfico 9. Costos. Fuente: Universidad de Pamplona.

El indicador de rendimiento de ingresos operacionales expresó el porcentaje de ganancia de la operación obtenido sobre los ingresos operacionales del ejercicio.

Su comportamiento, que se observa en el Gráfico 10, determinó igualmente una disminución hasta el cuarto periodo, lo que demuestra poca representatividad durante el periodo en análisis.

\section{Palanca de crecimiento}

Para el análisis en la creación de valor en la universidad, se tuvieron en cuenta los siguientes indicadores: productividad del capital de trabajo (PKT), margen EBITDA -MEBITDA- y la palanca de crecimiento (PDC).

En el Gráfico 11 el mayor valor de la PDC fue en el periodo uno, lo que indica que el crecimiento de la universidad se perfilaba como atractivo, ya que agregaba valor. Sin embargo, fue decreciendo de los periodos dos al cuatro, 
y de nuevo incrementa en el último periodo. Es esta una situación desfavorable para la institución de educación superior, ya que ese crecimiento no generó valor en los niveles deseados.

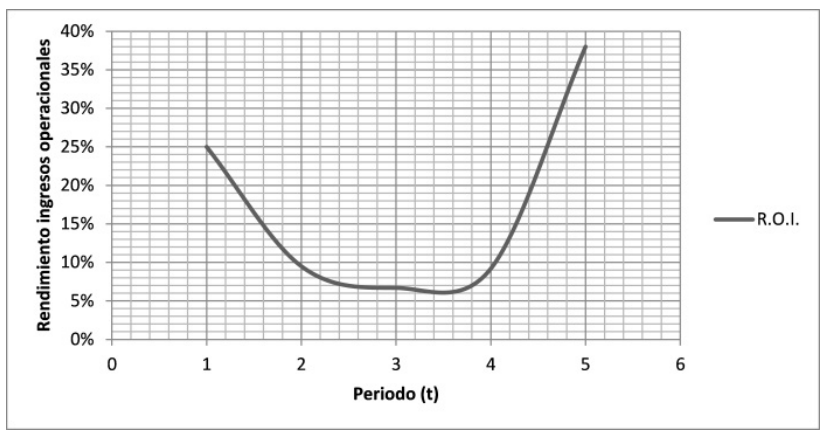

Gráfico 10. Rendimiento ingresos operacionales. Fuente: Universidad de Pamplona.

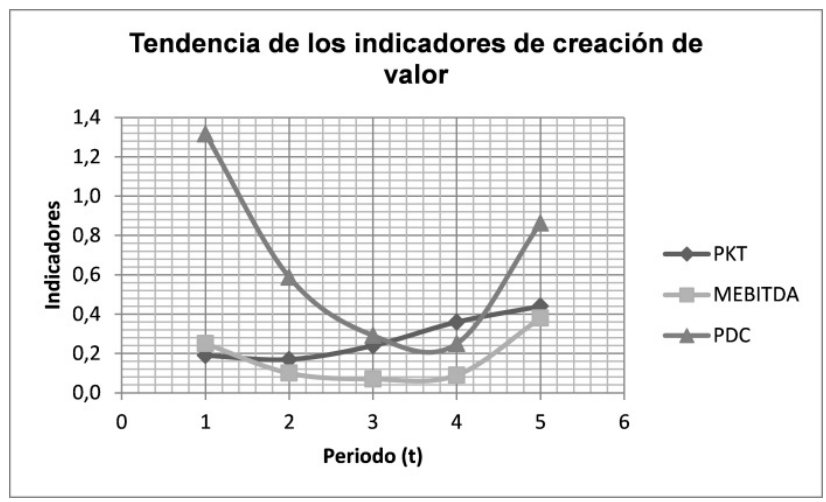

Gráfico 11. Tendencia de los indicadores de creación de valor. Fuente: Universidad de Pamplona.

Se colige un alto índice de crecimientos operacionales, representados en la venta de servicios educativos y de extensión, que se considera que no fueron debidamente planificados. Se logró determinar una disminución de acuerdo con los resultados de los indicadores de rentabilidad, lo que implicó una disminución del valor deseado, según el indicador PDC. Esto determinó una situación desfavorable para la universidad.

Es notorio que la institución de educación superior generó un crecimiento sin rentabilidad de sus activos, lo que explica una desproporción de la oferta académica y las matrículas. A pesar de que significaron un avance importante en la proyección del claustro universitario, no fueron lo suficientemente planificadas, lo que tuvo como resultado una disminución en la creación de valor.

Productividad de los activos fijos en la creación de valor
Se pudo constatar que la evolución del presupuesto de ingresos y gastos de los recursos propios, con respecto a la productividad de los activos fijos para la creación de valor en la institución, tuvo un crecimiento constante en la inversión. Esto es, un crecimiento superior al $50 \%$ del presupuesto, como se observa en el Gráfico 12.

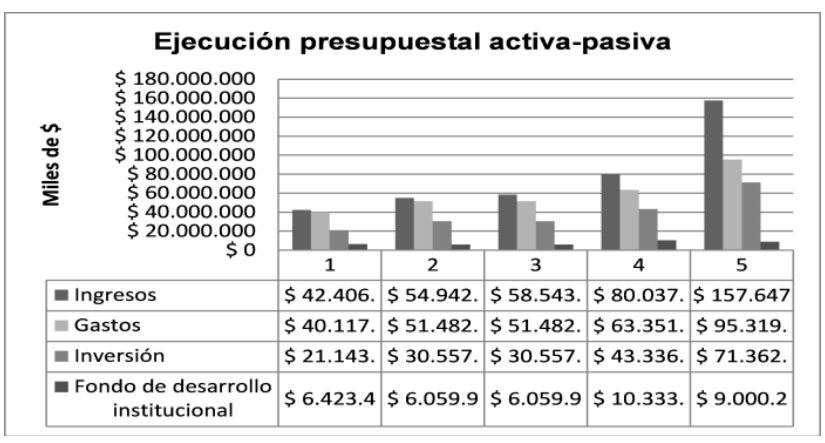

Gráfico 12. Ejecución presupuestal activa-pasiva. Fuente: Universidad de Pamplona.

El rubro del fondo de desarrollo institucional tiene relación con la productividad de los activos fijos, así como un comportamiento casi similar durante los tres primeros periodos, para posteriormente aumentar. No obstante, decreció en el último periodo, lo que generó una destrucción de valor.

\section{Indicador presupuestal de gastos}

El indicador presupuestal de gastos se calculó según las siguientes formulaciones (ver 3 y 4), en relación con los pagos totales realizados por la universidad, respecto al presupuesto total de gastos y los compromisos:

Indicador presupuestal de gasto $1(t)=\left(\frac{\text { Pagos totales }}{\text { Presupuesto total de gastos }}\right)$

Indicador presupuestal de gasto $1(t)=\left(\frac{\text { Pagos totales }}{\text { Compromisos }}\right)$

Los indicadores presupuestales de gastos dan como resultado la gestión por parte de la universidad en cuanto a los pagos, en relación con el presupuesto total de los gastos y con los compromisos adquiridos.

Se observa en el Gráfico 13 un incremento porcentual de los indicadores en los tres primeros periodos, así como un posterior decrecimiento en los últimos periodos.

\section{Rotación activo fijo presupuestalmente}

El Gráfico 14 muestra que el quinto periodo presenta el hallazgo más significativo, al ser la rotación más alta. 
Se obtuvo una colocación de 17,51 veces el valor de lo invertido en activo fijo.

La evolución del presupuesto de ingresos y gastos de los recursos propios, en relación con la productividad de los activos fijos en la creación de valor de la universidad, se observa en el Gráfico 15. Allí se comprueba que aumentó en el periodo 3-4 y reportó menos crecimiento en el periodo 1-2.

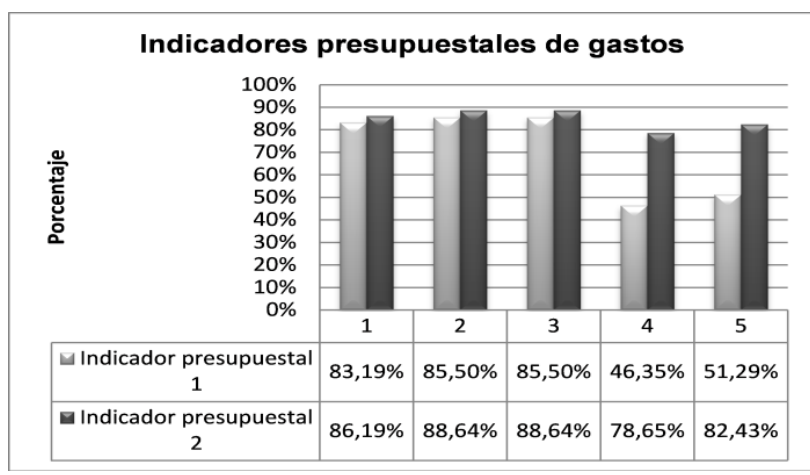

Gráfico 13. Indicadores presupuestales de gastos. Fuente: Universidad de Pamplona.

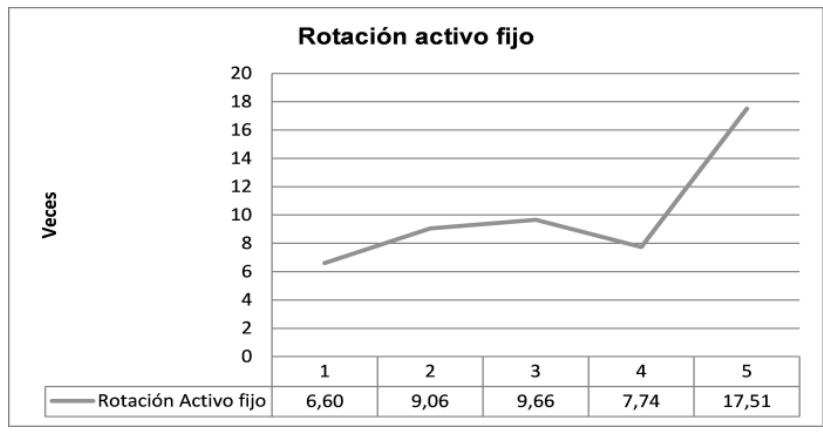

Gráfico 14. Rotación activo fijo. Fuente: Universidad de Pamplona.

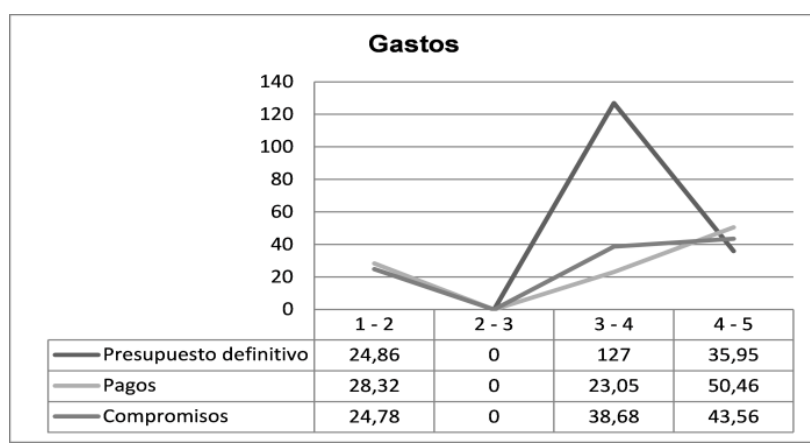

Gráfico 15. Crecimiento de los gastos. Fuente: Universidad de Pamplona.
En el Gráfico 16, se determina, en lo que se refiere al presupuesto definitivo de los gastos de inversión, que los crecimientos se presentaron en los periodos 1-2 y 3-4.

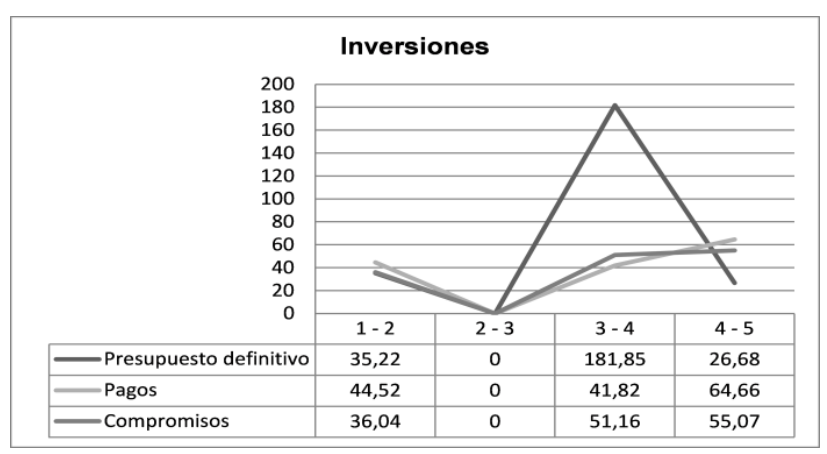

Gráfico 16. Crecimiento de las inversiones. Fuente: Universidad de Pamplona.

El Gráfico 17 muestra que el presupuesto de los compromisos del fondo de desarrollo institucional creció más en el periodo 3-4, y presentó los menores crecimientos en los periodos 1-2 y 4-5, respectivamente.

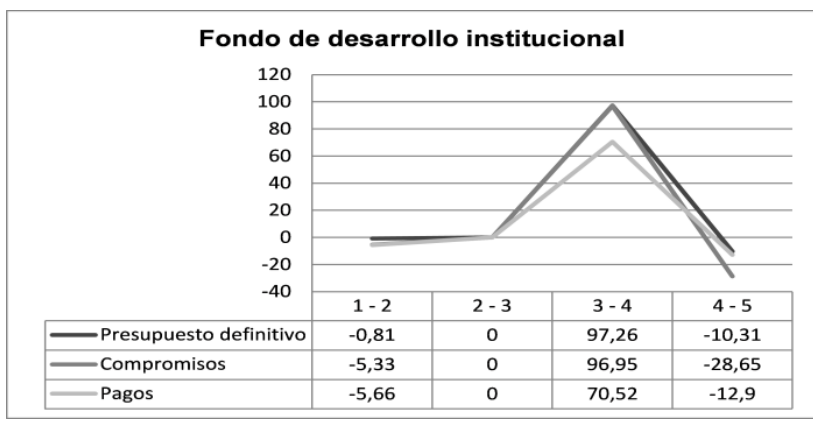

Gráfico 17. Crecimiento del fondo de desarrollo institucional. Fuente: Universidad de Pamplona.

Ingresos con recursos propios para le creación de valor

La liquidez es restringida en este escenario, porque los ingresos por concepto de matrículas se registran en dos momentos del año, y no existen mecanismos financieros que controlen efectivamente el manejo de los activos corrientes sobre los pasivos corrientes. Esto genera destrucción de valor.

El indicador de liquidez observado en el Gráfico 18 determinó que las mayores posibilidades de la universidad para cancelar las obligaciones en el corto plazo fueron las obtenidas en el cuarto periodo de análisis. Este, con el 1,76 , fue el más alto cociente. El menor cociente se registró en el tercer periodo, con 1,1. 


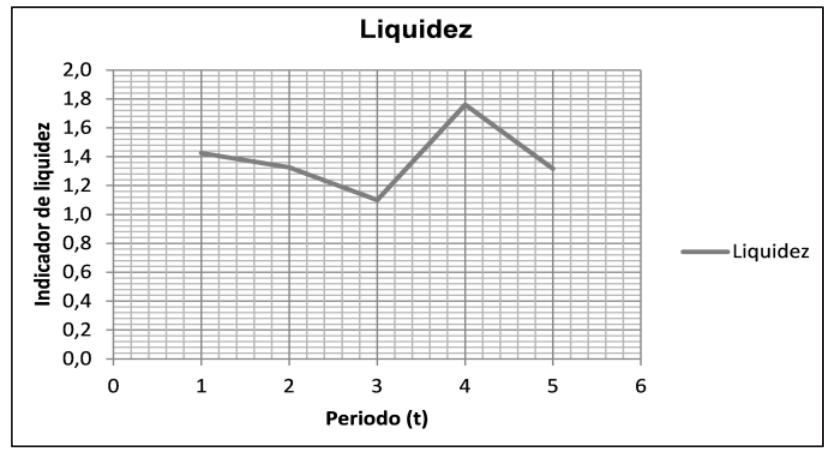

Gráfico 18. Indicador de liquidez. Fuente: Universidad de Pamplona.

El Gráfico 19 presenta el comportamiento de la relación en la institución del capital de trabajo neto (KTN) y el capital de trabajo neto operativo (KTNO).

El KTN presenta unos menores crecimientos durante los tres primeros periodos. En los últimos dos periodos, ocurren sus mayores crecimientos. El KTN se refiere a la unidad de caja, donde los recursos de los diferentes convenios ingresaron a un fondo común. Su impacto es un incremento en el activo corriente y un aumento en el pasivo corriente, debido a los compromisos adquiridos por los convenios.

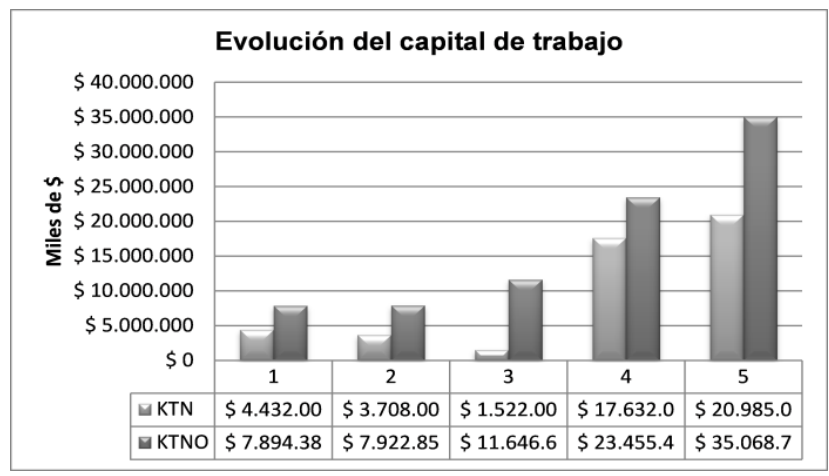

Gráfico 19. Evolución del capital de trabajo. Fuente: Universidad de Pamplona.

En cambio, el KTNO presenta un crecimiento desde el primer periodo en análisis hasta el último. Esto se refleja en un capital ocioso, lo que sugiere la no existencia de políticas adecuadas para el manejo del efectivo que permitieran optimizar los recursos disponibles. Esto ha ocasionado una destrucción de valor en el manejo financiero de la universidad.

El comportamiento de los activos fijos presentes en el Gráfico 20 indica un aumento anual desproporcionado de la productividad en activos fijos de la institución de educación superior. Aumento que estuvo destinado al mejoramiento de la capacidad física, tal como la construcción de laboratorios experimentales, obras de uso público y el establecimiento de la infraestructura tecnológica en el campus universitario.

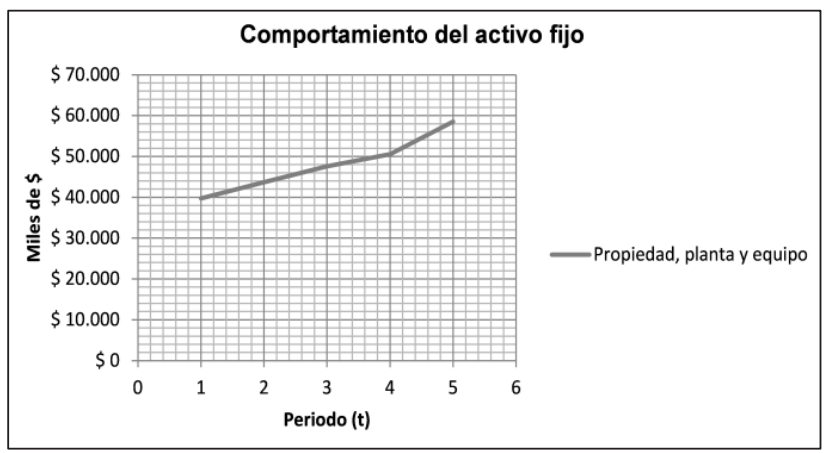

Gráfico 20. Comportamiento de los activos fijos. Fuente: Universidad de Pamplona.

La carencia de una planificación condujo a omisiones penosas, como la existencia de un estudio previo, de su costo y financiación que permitiera tener una rentabilidad adecuada en la adquisición de las inversiones. Con ello se habría evitado destruir el valor y poner en riesgo a la universidad.

El análisis de la liquidez a nivel presupuestal reflejó que las fuentes de ingresos por recursos propios cubrieron los gastos, de modo que quedaron compensados y se generó una diferencia a favor. Esto, sumado al margen por concepto de la administración de los convenios, lo que permitió mantener la infraestructura física de la institución de educación superior ubicada en el rubro de la cuenta fondo de desarrollo institucional.

\section{Comportamiento de la productividad de los activos fijos en la creación de valor}

En cuanto a la información presupuestal de la productividad de los activos fijos de la universidad, en el Gráfico 21 se observa un incremento anual no planificado superior al $50 \%$. Ello se debió a la carencia de políticas claras definidas en el presupuesto de inversión de la institución.

Se destaca una disminución en el rubro de la cuenta fondo de desarrollo institucional, en la que se registra presupuestalmente la infraestructura física de la institución de educación superior. Para esto, no se tuvo en cuenta el estudio de los costos y la financiación adecuada, lo que generó destrucción de valor. 


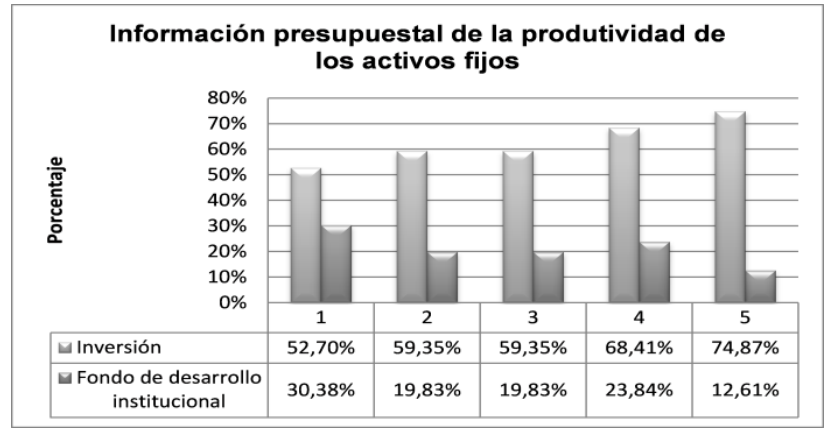

Gráfico 21. Información presupuestal de la productividad de los activos fijos. Fuente: Universidad de Pamplona.

En el Gráfico 22, en cuanto a la rotación del activo fijo, se observa que el indicador rotacional fijo midió la capacidad que tenía la universidad para utilizar el capital en activos fijos. Se destaca allí la colocación en el mercado del valor invertido en ellos, como puede visualizarse a partir del tercer periodo.

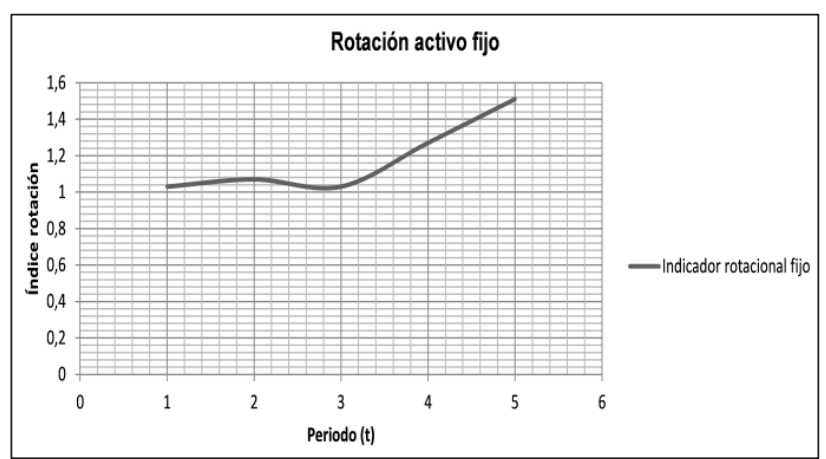

Gráfico 22. Rotación activo fijo. Fuente: Universidad de Pamplona.

En el análisis de la evolución del endeudamiento, el indicador reflejó la medición del grado y de qué forma participaron los acreedores en el financiamiento de la universidad, durante el periodo de análisis.

De igual manera, se trató de establecer el riesgo en que incurrieron los acreedores, el riesgo institucional y la conveniencia o no de un determinado nivel de endeudamiento.

El proceso de inversión de activos fijos enmarcó un endeudamiento que afectó la liquidez y el capital de trabajo. Esto puede identificarse en el pasivo concentrado en las obligaciones financieras.

En el Gráfico 23 se observa, a partir del tercer periodo, que el endeudamiento supera el $50 \%$, justificado en la no existencia de una debida planificación en la adquisición de activos fijos. Esto afectó directamente las finanzas de la universidad y determinó la destrucción de valor.

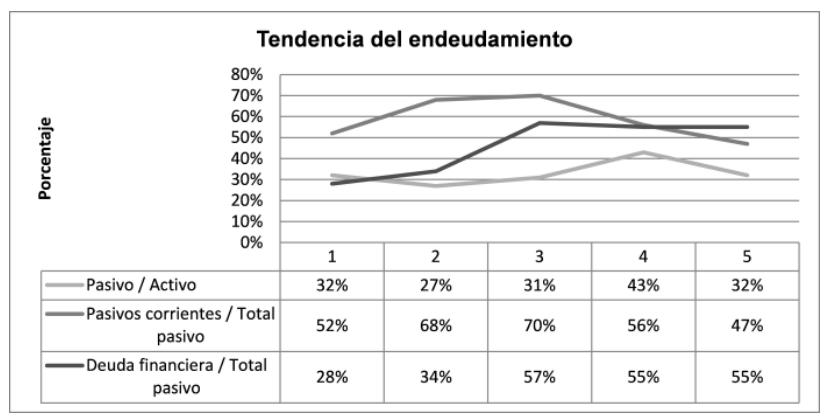

Gráfico 23. Tendencia del endeudamiento. Fuente: Universidad de Pamplona.

\section{Propuesta del modelo de creación de valor}

El modelo de creación de valor propuesto para medir la expansión y el crecimiento en la universidad pública se soporta en la operacionalización de las variables definidas en la Figura 1. Este modelo permite analizar y describir, a través de la estadística descriptiva, los comportamientos de los respectivos subindicadores e indicadores asociados a las variables, fuentes de recursos propios, presupuestos de ingresos y gastos, liquidez, capital de trabajo y activos fijos que están relacionadas con la creación o destrucción de valor (ver Figura 1). 


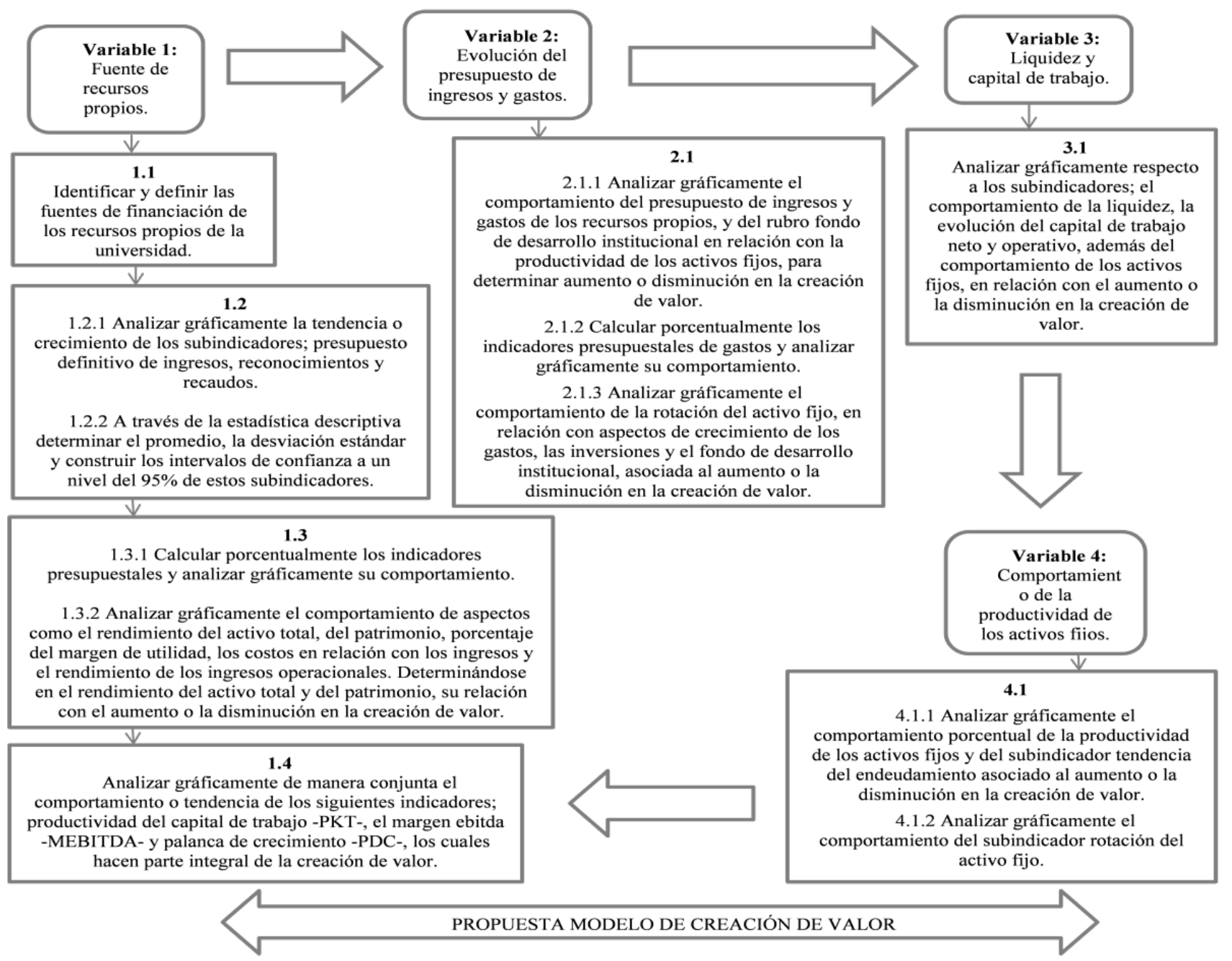

Figura 1. Propuesta modelo creación de valor. Fuente: Autores.

\section{Conclusiones}

Al inicio del documento, se señala que el objetivo era presentar la propuesta de un modelo de creación de valor para la universidad pública. Este modelo, resultado del acercamiento a la revisión teórica de la gestión de inductores de valor y la palanca de crecimiento, había de coadyuvar a las vicerrectorías administrativas de las instituciones de educación superior en el manejo financiero y el control de los recursos institucionales. De esta forma se concluye lo siguiente:

- Se evidencia que no se planificó financieramente la creación de valor, en el proceso de expansión y crecimiento, por lo cual este tuvo una disminución. No se efectuaron claramente los lineamientos en las inversiones de activos fijos sobre la liquidez y el capital de trabajo, sin tener en cuenta los requerimientos de financiación y costo. Por esta razón, perdió valor.
- Se concluye que la universidad reflejó un proceso de crecimiento sin rentabilidad, lo que ocasionó una destrucción de valor mediante la aplicación de la palanca de crecimiento. Esto afectó la liquidez y el capital de trabajo.

- Se infiere como resultado de esta investigación que cuando se incrementan las inversiones mediante la rentabilidad de los activos de la institución universitaria y se determinan los flujos de caja que inciden en las decisiones financieras, estas acciones permiten una permanencia y crecimiento que dan lugar al aumento de valor, para garantizar la sostenibilidad económica y financiera de la universidad pública en el tiempo.

\section{Referencias}

Burbano Ruíz, J. E. (2010). Presupuestos: un enfoque de direccionamiento estratégico, gestión, y control de 
recursos. Bogotá, Colombia: McGraw-Hill.

Calva Mercado, A. (2001). Medición de la creación de valor económico en la empresa. Recuperado de http://www.ee-iese.com/111/pdf/lese_111_Alta.pdf

Didriksson, A. (2005). La universidad de la innovación. Una estrategia de transformación para la construcción de universidades del futuro. México: CESU / Plaza y Valdés.

García Serna., O. L. (2009). Valoración de empresas, gerencia del valor y EVA. Medellín, Colombia: Editorial Express Ltda.

Gitman, L. J. \& Zutter, C. J. (2012). Principios de administración financiera. México: Pearson Educación.

Meigs, R. F., Bettner, M. S., Haka, S. F. \& Williams, J. R. (2001). Contabilidad: La base para decisiones gerenciales. México: McGraw-Hill.

Ministerio de Educación Nacional (1992). Ley 30, Por la cual se organiza el servicio público de la Educación Superior, 28 de diciembre de 1992. Título tercero, capítulo V.

Otal Franco, S. H. \& Serrano García, R. (2006). Reconocimiento y valoración de los activos fijos no financieros en las normas internacionales de información financiera. Saberes: Revista de estudios jurídicos, económicos y sociales, (4), 1-34.

Paz-Marcano, A. I., Sánchez-González, J. A., \& SánchezValbuena, I. J. (2018). Responsabilidad social factor integrador en Universidades Públicas. I+ D Revista de Investigaciones, 12(2), 37-46.

Pérez González, D. (2005). Contribución de las tecnologías de información a la generación de valor en las organizaciones: un modelo de análisis y valoración de la gestión del conocimiento, la productividad y la excelencia en la gestión (tesis doctoral). Universidad de Cantabria, Cantabria, España. Recuperado de http:// www.tdx.cat/handle/10803/10587

Porter, M. E. \& Kramer, M. R. (2006). Strategic and Society: The link between competitive advantage and corporate social responsibility. Harvard Business Review, 84(12), 78-92.

Rincón de Parra., H. de C. (2005). Contabilidad de costos y de gestión en la industria farmacéutica venezolana: estudio de un caso. Revista Venezolana de Gerencia, 10(30), 267-287.

Rodríguez Martín, J. A. (2004). El presupuesto de la nación: una evolución empírica del gasto (tesis doctoral). Universidad de Granada, Granada, España. Recuperado de http://www.ugr.es/ josearm/

Romero, J. (2003). Presupuesto público: presupuesto de ingresos, gastos e inversión. Bogotá, Colombia: Ecoe Ediciones.

Simanca, F. A., Porras, A. A., Garrido, F. B., \& Hernández, P. C. (2017). Implementación de herramientas tecnológicas en los procesos de enseñanza- aprendizaje de los triángulos. I+D Revista de Investigaciones, 10(2), 79-88. Soto Durán, M. del P. (2010). La creación de valor en la Universidad de Pamplona: periodo 2003 - 2007. (tesis de maestría). Universidad Nacional Experimental del Táchira, San Cristóbal, Venezuela.

Van Horne, J. C. \& Wachowicz, J. M. (2010). Fundamentos de administración financiera. México: Pearson.

Vera Colina, M. A. (2006). Gerencia basada en valor: la inclusión del costo financiero como un costo de oportunidad. Actualidad contable FACES, (13), 154165. 